Article

\title{
Pathways to Equitable and Sustainable Education through the Inclusion of Roma Students in Learning Mathematics
}

\author{
Javier Díez-Palomar ${ }^{1}{ }^{(1)}$, Ainhoa Flecha Fernández de Sanmamed ${ }^{2}$ (D), Rocío García-Carrión ${ }^{3, *}$ (D) \\ and Silvia Molina-Roldán 4 (D) \\ 1 Faculty of Education, University of Barcelona, 08035 Barcelona, Spain; jdiezpalomar@ub.edu \\ 2 Department of Sociology, Autonoma University of Barcelona, 08193 Barcelona, Spain; Ainhoa.flecha@uab.cat \\ 3 Faculty of Psychology and Education, University of Deusto, Ikerbasque Research Fellow, \\ 48007 Bizkaia, Spain \\ 4 Department of Pedagogy, University Rovira i Virgili, 43007 Tarragona, Spain; silvia.molina@urv.cat \\ * Correspondence: rocio.garcia@deusto.es; Tel.: +34-944-139-003
}

Received: 15 May 2018; Accepted: 22 June 2018; Published: 27 June 2018

check for updates

\begin{abstract}
Education is a key feature in the development of an agenda for a sustainable world. Education usually is associated with developing a responsible and ethical citizenship, aware of the main challenges for a sustainable development. Mathematics used to play a role as gatekeeper to achieve good educational performance. This article explores six case studies of Roma developing successful learning stories in learning mathematics. We identify five main characteristics in their educational trajectories that may explain Roma students' success in the school. This article moves forward previous studies characterizing Roma cultural features of mathematics learning, reporting stereotypes towards Roma in school. We conclude that in order to promote educational inclusion, successful stories may inform effective educational programs that, ultimately, may lead towards a sustainable education, including students from the most disadvantaged groups, as in the case of the Roma people.
\end{abstract}

Keywords: sustainability; Roma children; education; mathematics teaching and learning; transformative learning; social change

\section{Introduction}

This article discusses how six Roma individuals have been able to address social and cultural stereotypes developing a successful learning story. Their struggle to overcome inequalities provides insights to counteract the situation of exclusion that many Roma students suffer in mainstream schools. In this study, some contributions and suggestions for transforming education leading to social change and how to deal with cultural minorities in the school are presented. The final statements of this article are supported by an exploratory study, based on the use of qualitative methodology. This case illustrates a potential approach to fulfil the United Nations (UN) Sustainable Development Goals to transform education for a better world. First, we justify the pertinence of this work in the context of a transformative learning for a sustainable education. Then, a literature review is presented, followed by the methodology used. Drawing on such analysis, we aim to answer the question: Which characteristics of the educational trajectory of Roma people have contributed to their success in learning mathematics? Failing in including the largest ethnic minority in Europe, the Roma people, there is unlikely initiative for European educational systems to be equitable, inclusive and sustainable. The data collected is discussed in the main section of this article. Some preliminary conclusions are presented at the end, providing suggestions for further research that may further explore this contribution. 


\section{Theoretical Framework}

\subsection{Education as a Key Feature to Overcome Inequalities and Transform Societies}

The role of education is well established as a transformative instrument to overcome inequality [1-3]. Education is one of the main cornerstones set up by the UN to develop its 2030 Agenda for Sustainable Development, aiming at coordinating country "efforts to end all forms of poverty, fight inequalities and tackle climate change, while ensuring that no one is left behind" [4]. The fourth goal of this agenda is addressed to ensure inclusive and quality education for all and promote lifelong learning. According to the UN, obtaining a quality education "is the foundation for improving people's lives and sustainable development" [4]. Long-term sustainability depends on the development of human capital, and education plays a key role in such endeavour [5]. Hence, in order to achieve the goal of creating a sustainable world based on equity, inclusiveness, peace, social justice and cultural competence, no one must be left behind [6]. Data show that higher levels of education are associated with better employment opportunities and higher income [7]. Thus, having a higher level of education where critical thinking is developed offers better opportunities to enjoy better life standards and may impact on personal behaviour for a more sustainable world.

Drawing on previous literature, we know that mathematics performance is a gatekeeper in education: students who overperform in mathematics are more likely to achieve better scores and end with better educational trajectories, than students who underperform in this subject [8,9]. According to Parker and his colleagues [10], math self-efficacy is a statistically significant predictor of university entry. Balfanz, Herzog and Mac Iver [11] warn that failing mathematics in sixth grade is a highly reliable predictor of students not graduating at the end of compulsory education. Overcoming such situations demands development of successful educational actions to meet the UN goal of inclusive education for all.

However, in order to fulfil this goal, many (social, gender and cultural) inequalities must be tackled. Discrimination either based on socio-economic status, gender or cultural heritage are meeting points underlying situations of exclusion and oppression [12,13]. Inequalities between socioeconomic groups are often associated to unequal school attainment and continuity in post-compulsory education [14], which cannot be separated with the segregation of students according to their cultural and social background, frequently observed in European schools [15]. Statistical data from international organizations [16,17] suggest that children with minority background perform lower than those belonging to the mainstream, especially in subjects such as mathematics or reading comprehension. This is a general trend in all OECD countries. In Spain, Roma children are more likely to underperform and leave the school earlier than the mainstream population: statistically, six Roma abandon the educational system without completing the compulsory level, versus less than two non-Roma individuals in the same situation [18].

Reaching the UN goal of inclusive education and moves towards a sustainable world entails not only avoiding students' segregation according to their individual, cultural, social, or ethnic identity but also ensuring equal learning opportunities and achievement for all, to ultimately foster social inclusion [19]. In the case of students with a disadvantaged background, an education based on high expectations and rich curricula becomes a lever to overcome educational inequalities [20]. This may be the case for Roma students. In this article, we focus on the case of the Roma as a potential example to build success stories from high-excluded people and provide some insights to meet the UN goal of having an inclusive education for all.

\subsection{Prejudices and Racism Towards Roma}

Most of the scientific studies on Roma people suggest the existence of racism against this ethnic minority in the classrooms. In some countries, like Hungary, with an average of students with special needs (SEN) higher than the European one, Roma children are routinely placed in special schools [21]. Petrokou and Dimitrakopoulas [22] in a study about the academic performance of Roma students claim that some education authorities state with no evidence that 'Roma families do not really want 
their children to attend school ( . . ) the Roma are reluctant to integrate into society ... ' [23] (p. 630). Revenga, Ringold and Tracy [24], drawing on a comparative household survey about living standards among Roma, conducted in Hungary, Bulgaria, and Romania, show that there is a positive correlation between ethnicity and living standards. Fox [25], based on the information available in the Minorities at Risk dataset, collects the main discourses about Roma people, including the biased and racist image of Roma as 'dirty, lazy and stupid people who are prone to crime' [25] (p. 3).

This 'picture' use to appear in what Chronaki [26] and others [27] call 'gypsiologists'. According to them, the gypsiologist discourse tends to naturalize Roma images based on prejudices and stereotypes with no real evidence [28-32]. Previous research suggested that engaging Roma students and their families in school through dialogic learning was a particularly successful approach to "turn difficulties into possibilities" [33]. The study conducted by Flecha \& Soler [33] challenged many prejudices towards the Roma, developing a community-based school that has shown to be sustainable over time for more than ten years and creating avenues for inclusion and success of Roma students in the most challenging circumstances.

\subsection{Roma within the Literature on Mathematics Education}

There are not many previous studies about how Roma perform in Mathematics education [26,34-36]. The few existing studies on this topic suggest that Roma students (as a cultural group) must face a conflict between the legitimated educational discourse, what Bernstein [37] called elaborated code of the school, based in the idea of paper-and-pencil teaching and learning, and Roma own oral culture, rooted in their particular cultural heritage. Schools produce a habitus, in Bourdieu's terms [38] excluding Roma students from the mainstream discourse. This fact, alongside socio-cultural stereotypes against the Roma heritage, produce a situation of poor expectations, as presented by Hudley [39], about what Roma students may learn in the school.

In order to transform this situation, Chroniaki [34] draws on Gutiérrez, Baquedano-López and Tejada's concept of hybridity [40]. Chronaki suggests introducing hybrid practices as a way to break with the monologic discourse of the school [34]. Drawing on Bakhtin's [41] concept of polyphony, Chronaki argues the need to develop dialogic practices to include the voices of all students within the classroom, not only the ones who share the monologic hegemonic discourse. Other studies denounce the unfair situation that Roma students face in the mainstream schools [36], but not further ideas about how to overcome this condition.

\section{Methods}

In this article, we address the research question of which characteristics of the educational trajectory of Roma people have contributed to their success in learning mathematics? This study is part of a larger research project investigating the response of individuals from ethnic minorities to overcome the [social] inequalities they face in the educational system when learning mathematics. This research interest emerged in the frame of analysing how children at risk are able to find their way to succeed in school, developing successful educational trajectories. When conducting this study, we argued that Roma people developing successful learning stories (in mathematics) usually have a strong support from their relatives, which contradicts what is suggested by the few studies on this topic [35].

In order to better understand their process of learning when trying to identify successful features in an educational trajectory to transform the learning of mathematics, we decided to conduct a qualitative exploratory case study. Drawing on Flick, "the aim of case studies is the precise description or reconstruction of a case" [42] (p. 147). Having in mind these words, we decided to use an exploratory approach, as according to Blumer [43], exploratory studies are special cases because they allow us to address situations or phenomena which are not yet known but only constructed in the course of the investigation. 
This qualitative approach is appropriated to, firstly, identify those aspects that may explain individuals' successful stories in learning mathematics, that may be discussed (confirmed or rejected) by further quantitative research. In this article we explore the personal narratives that allow us to see first-hand the interpretations made by the protagonists of their own life experiences. As Bruner [44] claimed, we understand our world through the lenses of personal narratives. In addition, we also make meaning, an even build meaning, through those narratives. This type of method (inquiry) led us to include the voices of the participants within the study.

\subsection{Selecting the Participants in the Exploratory Study}

In this study, we conducted a series of in-depth interviews with six Roma individuals. The selection was constituted by accessibility [45]. We used this approach since previous studies suggested that Roma people usually refuse to cooperate with non-Roma researchers because of the long history of exclusion and non-recognition in scientific research [46]. In order to deal with this challenge, we designed our case study in collaboration with two Roma individuals who act as co-researchers to access the Roma community. We used a deliberate purposeful sampling to select six Roma individuals. The criteria used for their selection were:

1. Being Roma.

2. Having a successful academic trajectory (or being at that moment developing such trajectory). In this context, success is defined as "the completion of the degrees they studied, this is, not having dropped out or left school early".

Based on these criteria, we called on contacting a regional programme for the inclusion of Roma people to have access to some of the participants. These participants, in turn, facilitated access to other people that fulfilled the criteria, following the snowball sampling strategy.

All of the participants were aged between 22 and 38 and had achieved different educational levels. The six individuals participating in this exploratory study were:

- Federico, born in 1984. He holds a university degree in education (Ph.D.).

- Joana, born in 1990. She holds a university degree in education (Ph.D.).

- Joaquim, born in 1988. He completed primary education.

- José, born in 1979. He holds a VET degree in education.

- Antonio, born in 1996. He holds an upper secondary degree of education.

- Aroa, born in 1996. She holds an upper secondary degree of education.

All names used in this article are pseudonyms, to protect the anonymity of the participants in the study, applying the Ethics for researchers procedures set up by the Directorate-General for Research and Innovation from the European Commission [47].

Data collection included a set of personal narratives with them. This method of inquiry is rooted in previous works, such as the ones by Thomas and Znaniecki [48], Garfinkel [49] and Mills [50]. It involves collecting the testimonies of people participating within the study [51] through a number of instruments, including life stories, self-reports, oral biographies memories, testimonies, in-depth interviews, recorded narratives and life review [52,53]. Interviews were conducted as best suited for the interviewees; researchers were flexible and adapted to the hours and places proposed by the participants. The research objective was shared with the interviewees before starting the conversation in order to allow focused reflection on the topic of study. All participants provided their informed consent to be part of the research.

\subsection{Data Analysis}

In order to analyse the data collected, we used narrative and discourse analysis [52,53], drawing on grounded theory [54] and the communicative methodological approach [55,56]. This approach focuses 
on the analysis and interpretation of the discourse drawing on the dialogue with people involved in the study, using validity claims [57].

Interviews were audio-recorded and transcribed verbatim for further analysis. Transcripts were carefully examined to find relevant elements for us to identify characteristics in their educational trajectories for succeeding in learning mathematics. Five emerging categories referred to individual strategies, social representations and identity, teacher interaction, peer interaction, family and community interaction. Interviews were analysed through the lenses of these categories.

When conducting a second round of interviews, researchers and participants established a shared dialogue to jointly explore the data analysed. That dialogue allowed us to revise and agree on those meaningful experiences in their learning trajectories.

\section{Results}

The six individuals share common features in their personal narratives. All of them had faced difficulties turning prejudice into success during their academic lives, although their strategies have been somehow different. Federico narrates how he used to like challenging tasks because it was an 'opportunity for learning'. However, he always turned back to his family (especially to his mum), looking for her support to solve the mathematics. On the contrary, Joana was a different case. She also liked schooling, but mathematics and challenging tasks were a nightmare. She struggled with mathematics during her academic learning trajectory. In her case, she used to ask her peers to solve her difficulties, working together in small groups. Federico and Joana are two examples illustrating the facts that may explain their final success, as both were able to achieve their academic degrees. Next, we present the main features emerging from the data analysis.

\subsection{Successful Individuals' Strategies to Overcome Barriers When Learning Mathematics}

José is talking about his school experience. While he is narrating that he was considered a good student, although sometimes he did not obtain good scores. When we ask him: 'How did you use to study?' he replies: 'I used to study long before the exam. Outlines always worked for me'. Studying and devoting themselves to the task is a common strategy for some of the other participants in the study. That is also the case of Joaquim, Joana, Federico, and Aroa. All of them agree: studying is the key. Some of them, like José, used to study just before the exam; others, like Aroa, spent full days studying, to learn everything. This shows a 'growth mindset' [58] among them, this incremental approach to intelligence seems ever more important for Roma children to succeed. If they work hard and find their own strategies, they can do it. Federico describes his process as follows:

My trick was summarizing the lesson, like drawing schemes. A trick that I used a lot for theoretical questions was to remember keywords, so after that, I was able to remember the whole definition because of the keyword. Regarding the practical cases, the trick that I used the most was looking at examples such 'type' problems, and then learning by heart the equations like 'reading' them, not memorizing them. For example, the Pythagoras theorem: instead of memorizing $h^{2}=c^{2}+c^{2}$, I learned to read the equation, so I still remember it; the squared hypotenuse equals the sum of the square sides (cathetus).

Joaquim's case was somehow different. He is a 26 years-old man. During his childhood, he was a conflictive student. He did not like studying. However, he used to obtain good scores; in fact, talking about mathematics, he declares himself as a good student. However, as for the other participants, for him, the key aspect was 'studying and perseverance'. He uses these two words several times in his narrative. According to him, the key aspect explaining his late academic success (because after several years, he went back to the school in a 'second chance' program) was 'perseverance, effort, and a great teacher'. 
Although studying is the common strategy emerging from all six narratives, other variables also appear. This is the case of motivation. Motivation became the 'reason' to keep studying for many of our participants. José claims that the key aspect was 'my will to learn' and 'my determination'.

Motivation also appears in Federico's discourse. Federico explains that he always liked mathematics and science. In fact, when he started attending the university, he first signed up for Biology. He studied for 1 year before he discovered his passion for teacher training: he wanted to help other Roma children to succeed in school as he did. He loved mathematics and science, but he never appreciated language and humanities. As we can see in his narrative, he did not receive support from his literacy teachers; instead, he got lower assignments to pass these subjects at the end of the year. Something similar happened to Joana, but in the opposite way. She preferred languages rather than mathematics, which was the most difficult subject for her. Joana complains several times because she used to obtain 'just' B's in mathematics, so she felt discouraged many times from learning it. This confirms a wide array of research that has shown the impact of quality teaching on students' performance $[59,60]$.

For Joana, her key strategy was perseverance, having good habits of studying, and being demanding with her own goals. She provides details of her learning strategies raising metacognitive awareness in the learning process:

During elementary, middle and high school I was not used to preparing the exams more than 2 days ahead. The school timetable was hard, and during the afternoons I used to attend a workshop, so I had to take advantage of every single opening in the late afternoon, or in the night, to study. When I was in elementary, I used conceptual schemes. In middle and high school, I studied nearly every time from the book and my notes, underlining the more important things and memorizing them. In the university I did not memorize that much; first I tried to understand the concept, and then I memorized a way to represent it, so it was easier to remember it later on. In the university, I also studied using notes, and I also underlined books and summarized some of them.

When, despite all the effort studying, Joana was not able to understand the lesson, she explains that she used to meet her friends to study together (and she still does the same practice).

In order to understand some ideas that I was not able to understand, I used to study in-group, with my peers: they explained to me what I was not able to understand by myself.

\subsection{The Power of Social Interaction for Learning and Identity Formation}

Peer-to-peer interaction appears as another possible factor to understand and explain the success of these six persons. However, peer-to-peer interactions are no guarantee of producing effective 'learning'. For instance, Joaquim used to participate in groups of peers marked by a declared and explicit resistance against schooling. As a consequence, he dropped out of the school (in elementary); and he never went back until he realized as an adult that school and education are important things. His group of peers did not value school, nor what was taught there. He was a good student though; he used to get good grades. However, after elementary school, he decided to drop out of the school. The 'bad example' of the popular guys in his group encouraged him to abandon his studies.

Joana's case, on the contrary, was very different. She also found it difficult to move from elementary to middle school. The change was traumatic for her. She lost many [Roma] friends along the way from elementary to middle school. She felt alone many times. That feeling was combined also with the fact that she did not find any commonalities between her cultural heritage (in terms of personal identity) as a 'Roma woman' and the identity of her classmates in the middle school. She did not find any place to fit her 'funds of knowledge' [61,62]. The situation was even harder when she moved from the high school to the university. There were no Roma in her group in the university. In addition, she was receiving pressure from her grandma because she asked her to get married and leave her academic trajectory. Joana explains that her dad was her main support at that 
time. He, as well as her mom, gave her support to overcome the difficulties and persist until being a doctoral student, already graduated as a lawyer, with a Master's degree in Human Rights, and finally, she got a Ph.D. degree.

\subsection{Successful Teachers' Practices Teaching Mathematics}

All the participants in this study agree in highlighting the key role that teachers perform in relation to children's achievement. Teachers have the ability to encourage students, helping them to obtain the best out of themselves. However, the opposite is also possible: teachers may project on students their own stereotypes, making the learning process even more difficult. This has been a recurrent issue when talking about the relationship between teachers and Roma students. Teachers are not alien to social rejections against 'being Roma', and many times they project low expectations on their Roma students, because of their ethnic identity. Such kind of attitudes influences definitely on teachers' behaviour within the classroom, as well as one the academic decisions they take. Federico is categorical in this regard:

Unfortunately, yes. Teachers used to have low expectations on Roma students. Although it was not the case with me, I saw it in other cases close to me. I think that two things happen: if you are a good student, then it is OK, or at least you have fewer problems ... You are 'one more student, like the other ones'. However, if you are Roma and you also have some learning difficulties, then they [teachers] start explaining your difficulties because you are Roma, because of your origin, your family ... I remember the case of one of my cousins ... She always was a bad student ... when she attended elementary school in 3rd grade, she had a lot of problems with reading. The teacher always said to my uncles that it was OK, it was not important at all, especially because after 6th grade she will leave the school, so they [my uncles] should not worry about her ... because she could learn to read later on.

This social representation about Roma girls dropping out at the age of 12 might be influenced by the idea of their getting married at an early stage in life [63]. This stereotype might justify the teacher's decision of reducing expectations related to the Roma girl in terms of attainment. It is not the case that teachers help less Roma students, but they do so because their practice is informed by social stereotypes. Federico declares:

Teachers spend a lot of effort and resources: individual lessons, small groups, extra [adapted] work, personal teachers ... the fact is that they invest all these resources in the wrong way, and they stigmatize us since we are very young as the dumb children in the classroom, or the ones who will become just workman or street vendors. ( . . ) you only need to go for a walk around any 'ghetto' with Roma people living in there and visit the schools. Roma have a whole classroom, with teachers just for us ... Teachers think that they help us better by doing that, but in fact, they are wrong ...

Teachers' expectations play a key role in terms of students' success or failure. If they decide that a student is excellent, thus they pose challenging tasks and demand effort from him/her, then that child would have more learning opportunities than those children who, from the very beginning, are labelled as 'unable to learn'.

I am one of those lucky students who was trusted by their teachers, so they [the teachers] raise their expectations each time to encourage us to learn more. Today I remember equations, problem-solving, and many topics in mathematics that I would have never learned without that support...

Joana, Joaquim, José, all of them claim that teacher decision about the presumed 'ability' of the student is crucial. Joana, like Federico, claims 'In my case, my teachers of mathematics treated me in the same way they did with the other children'. This egalitarian treatment is what Joana highlights over 
her narrative as one of the reasons to explain her success. José highlights again that using exclusionary practices, such as streaming within the classroom, or other segregating practices, may explain poor achievement of Roma children.

I think that the lower is the level in the group, the slower is the lesson's rhythm. So, children learn less content, or at least, they spend less time to go deeper [into the mathematical concept under study].

\subsection{Impact of Social Representations about Roma}

There is a plethora of scientific literature confirming the existence of social representations about the Roma identity [63]. However, what is not usual is the inclusion of the voices of Roma, thinking about the impact that those representations have on their own People [64]. The six people participating in this study are very aware of the dramatic impact of their 'identity' as 'Roma' in their educational stories. The difficulties that all of them have had are rooted in stereotypes about the Roma identity. When we interviewed Aroa, Federico, Joana, José, Antonio and Joaquim we asked them the same question: 'Some studies affirm that Roma children (boys and girls) obtain poor attainment because teachers use to place them on low-level groups. Do you agree with this statement? Why?' Almost all of them answered affirmatively to this question.

Segregation within groups of low-achievers, lack of incentives, 'passivity' of some teachers because (according to some of the interviewees) those teachers think that Roma students never will perform successfully in the school, are recurring themes in the testimonies of Federico, Joana, José, and Antonio. Only Aroa stands out from this general opinion, and she says:

I do not agree, there are both payos (non-Roma) and Roma included in the groups of low-achievers; they belong to that profile of students who would never obtain good scores, because they never got the requested knowledge to achieve that grade, because no one gives them that knowledge and this means that these students never get the same level as their peers, so they remain again and again in the low-achievers' group. (Aroa)

Aroa does not attribute the low academic level to the fact of 'being Roma' (exclusively). Someone may be Roma (or not), and being confined in the low-achievers' group. However, what makes the difference is the fact that Roma children are always placed within the 'group of low-achievers'; they always lack the opportunity to learn the kind of knowledge that is needed to pass the grades. Moreover, Aroa asks a challenging question for teachers:

Now it is me who is asking: the students who remain in the lower-achievers' group forever, during the whole elementary school ... why? Which is the reason to justify that? Maybe can we say that teachers are not that good? Because year after year, children never learn the concepts in the curriculum. (Aroa)

When we analyse mathematics education, social representations about Roma also arise. There is a shared agreement on the fact that Roma people have a special ability for mental calculation. Roma people are very proficient using different algorithms to do the arithmetic calculation (leading digit, compensation, break and bridge, rounding, adding up by $10 \mathrm{~s}$, adding up by using partial calculations, piecemeal, half and double, etc.). The reasons to explain it are diverse: Joaquim, for instance, claims that it is due to the fact that Roma have been trading makers traditionally 'because of the talent that Roma people have to trade'. The street markets, mercadillos, retail sales, are common 'spaces' or 'activities' for Roma. Even some of our interviewees have been involved in such kinds of activities, at some point. Aroa, when she was a child, after leaving the school, or during the weekends, used to help her parents and uncles in the street market. Over there, 'negotiation' was the rule: they must reach agreements between the number of goods for selling, and the price asked for everything, in order to make a profit. Joana's testimony illustrates this idea: 
I think that the experience of those Roma people used to make arrangements, and sell goods in the street market, to survive, may have something to do with that claim. I think that selling things gives them a special ability for numbers.

However, you might also calculate the amount (quantity) of product that you need to buy wholesale, thus neither over nor missing; because if you go over, you lose money; but if you get less than what you need, then you miss potential business. Aroa narrates how her mother, a Roma woman who never attended school, is able to calculate exactly the amount of product she needs to buy, hence not incurring losses and having a profit margin.

My mum never went to the school, but she really knew how many shirts she needed to sell in the market. She tracked how many we were selling, how many were left, if half of them, if all of them, if that week she was selling twice as usual, or if there were one-third left ... Then, meeting with my father and my uncles, she told them: look! We need this number of shirts and this other amount of this other thing...

In addition, the ability to calculate was also developed as consequence of being afraid of fraud, according to Federico's testimony:

My mom was illiterate. She was very scared of the fact of being tricked by numbers, with money I mean. Then, in my home, we always do mental calculation, a lot. We have done a lot of calculation, so that pushed us to develop our ability with mental calculation as well. But I will not state that this is a Roma ability, but the consequence of the type of situations that many Roma people address'.

Hence, the context also contributes to explain why many Roma people develop a particular ability for mental calculation; although, as Federico's claims, this is not specific for Roma people, but a consequence of the type of situations that Roma people are forced to address because of the context of social inequalities. This example illustrates the fact that home and school can be interlinked in a number of ways, offering opportunities to develop 'academic skills' such as [mental] calculation, which is an expression of what Bernstein [37] calls 'elaborated code' in his analysis of the type of discourse legitimated (and valued) in the school.

\subsection{The Role of the Family/Community in the Learning Process}

The support that Joana received from her father was crucial for her to end her university degree in the Faculty of Law. That support was essential in order to be able to face the difficulties along the way, in a 'world' where her Roma friends were absent. It was also crucial for her to resist other Roma women's comments to hurry her to get married, even coming from her own family (for instance, her grandmother). In her case, her family, her friends (with whom she shared her dream to continue studying), and her personal commitment, were all crucial factors to develop a success story in education.

They played an important role. They [parents] always helped me and they have shown me how important is education and the big opportunities that it brings to me. These words inspired me to keep working on my courses, especially because I was watching many others around me dropping out because they thought that school was not as important, so I was also questioning myself as well.

Federico's case, who also got a Ph.D. in Education, is similar to Joana's one. His parents many times were unable to support him to understand curricular contents from elementary school to university. However, 'in their own way', they supported him, giving him all the possible resources available at their disposal. 
My family always supported me and helped me, in their own way. They were not able to support me doing my homework with me, but I remember that during my courses my mother bought up to three encyclopaedias, because she said that as I was good in my grades, and I need to take advantage of it ... her way to support me was taking care of me so I had everything I needed.

Federico highlights the importance of transmitting the value of the education. He really appreciates his parents' effort to encourage him to study, both at home and in the neighbourhood, although they never had the opportunity to attend school due to their particular circumstances.

My family has not been able to contribute directly to my schooling. However, they gave me important values to be able to study. Especially, I would like to highlight the attractiveness of being successful in the school. I remember my parents being proud of me, explaining everywhere how clever I was, how much I was studying. Even now they do so. That always made me feel like wishing to study.

Federico's parents, his mother especially, looked for informal spaces to teach him mathematics, for instance, in the kitchen or when shopping. Over there we find situations clearly mathematizable. In addition, Federico's father, who worked in the construction sector, also used to teach him how to make a budget, take detailed measurements, calculate rates, prices, etc.

In an informal way, my mom taught me mathematics in the kitchen, or when shopping. Topics like volume, arithmetic, counting, prices, change,... My dad, as he was in the construction sector, taught me how to calculate budgets, how to calculate the price for square meters, how much does it cost the staff, rates.

Something similar was experienced by Joaquim. Narrating how he thinks his parents were helping him with mathematics, he explains that this support came especially in everyday situations: 'Counting change or how much he was expecting to spend'- he says-'when I was joining my mom for shopping'.

This support from the family is crucial. As Joaquim asserts,

Previously, [my parents] did not engage so much, because they did not have the background.

Now that I am taking my courses to go to the university, they are my major support and source of self-esteem.

Joaquim has been able to recover from a bad school trajectory truncated in elementary school. In his personal story, we are able to perceive clearly the impact of his family. This case is an example illustrating the experience of a Roma child living difficult times, with a family who never could take care of his education, because they had not the resources to do so. Many years later, and especially because of a 'new' family support (that now arises), Joaquim's life experiences a tremendous transformation, having the opportunity to have access to the university.

The role of the family is 50\% regarding schooling; now I know it because I am a father, but in my case, my parents couldn't help me because their educational level was really low, even nonexistent.

In the case of Joana, that 'support' is more aligned with what Hoover-Dempsey et al. [65] call 'reinforcement', that is, look for help to reinforce the learning of mathematics.

They helped me a lot. They put me into afterschool programs. They encouraged me. In fact, when I came to the university to register, I got many doubts, so I came back home; and then my parents encouraged me to go back and do so. So now I am the first one in my family with a university degree. Regarding mathematics, their help was not as evident, although in the street market I was requested to practice my multiplication facts. 
Due to the fact that her parents were not able to help her to do her assignments in mathematics, what they [the parents] decided was to send her to private lessons. As in the previous cases (Federico, Joaquim and Aroa), Joana's everyday life was full of opportunities to learn and practice mathematics in a practical way (in her case, within the street market).

\section{Discussion}

As stated in the UN goals, "obtaining a quality education is the foundation to improving people's lives and sustainable development." Starting from this premise, our study aimed to identify pathways to success when learning mathematics that would help deprived people to overcome educational exclusion. Succeeding in learning mathematics would put individuals, especially those systematically underserved, in a better position to improve their educational opportunities. As Balfanz, Herzog and Mac Iver [11] claim, failing mathematics in sixth grade correlates with leaving the compulsory educational system before graduating. Their data is highly consistent with later studies that confirm the same pattern [10]. Hence, we decided purposely to focus on Roma people because (a) they are the largest and one of the most excluded ethnic minorities in Europe; and (b) looking at the few available statistics [18], Roma tend to be the group of people with lower levels of education in Europe, especially from middle school on. Drawing on the learning of mathematics, as mentioned above, answering our research question would have the potential to provide good suggestions for policymakers and other stakeholders to inform educational interventions and programs to foster inclusion and sustainability.

Drawing on the analysis of the data collected throughout the narratives, several characteristics related to Roma students' performance arose. Those include:

- developing a growth mindset facilitates an academic identity based on values such as effort, the attractiveness of schooling, and motivation for learning;

- the importance of the teacher role in creating challenging curricular activities, increasing the opportunities for learning, based on high-expectations rather than social stereotypes about Roma people, and avoiding negative practices such as ability grouping;

- the role of the family looking for support and empowering Roma students about their capacity to perform successfully in the school;

- peer-to-peer interaction based on valuing schooling, establishing supportive "networking" (group work) based on solidarity and even generating solidarity-chains (students helping other students); and

- using "traditional" strategies as the rest of the mainstream students (such as studying to pass the exams, solving the classroom activities, doing the homework assigned, etc.)

The six cases analysed in this article suggest that Roma identity clearly influenced their school trajectories. Previous work like that conducted by Chronaki [26,34], Kertesi and Kézdia [35], or Stathopoulou and Kalabasis [36] provides evidence about oral practices, strategies to perform [mental] arithmetic calculation, oral ways to represent mathematics. This is consistent with the trajectories of the participants in our study and describes in detail how many Roma children learn mathematics. Poor performance of the Roma children pointed out in our data is linked to the lack of Roma positive representation in the school context based on teachers' prejudices and limitations to include them. This may explain why statistical data [18] shows a high level of drop out among Roma students, especially dramatic from middle school and onward. Some teachers fail in including the Roma in the school discourse where the mainstream culture is the main one legitimated [37]. However, what we have not been able to cover in this analysis is an explanation of the success of these few Roma who developed a successful educational story. What did they do to obtain their grades? How did they manage to overcome the socio-cultural barriers to develop their successful learning trajectories?

According to our findings, identity matters regarding the barriers that make learning difficult. A 'sociocultural' examination of the six narratives analysed reveals that teachers' social representations 
have a huge impact both on Roma students' opportunities to learn and also in their own expectations (self-concept) as learners. This phenomenon is well known in Social Sciences: Mead [66] already showed evidence of the fact that the individual identify (self) is defined by the social group. If a teacher sees a child as 'problematic', the child would act accordingly, because is 'what we expect from him/her'. However, when the child has an image as 'nice and hard worker', his/her behaviour would also be mediated by that social representation. Later studies confirmed Mead's findings $[67,68]$. This finding has been also confirmed in the field of mathematics education [69].

Our data also suggest that these social representations are powered by attitudes towards Roma children; but also, by social beliefs about this group. These representations impact people's beliefs about the Roma. In the school, the strategies used by many teachers to teach mathematics to Roma children are mediated either by a belief like 'they are good doing mental calculation' (which is a social representation about the image that Roma have as 'street vendors', 'dealer', 'illiterate', etc.), or because they prefer 'oral strategies' (because their culture is orally grounded). This ethnographic approach idealizes Roma as a traveller, a nomad person, which is false [70]. However, this is a claim that many teachers use to justify both lowering their expectations about Roma students and the kind of tasks they ask them to perform, tracking them into segregated academic paths with a different curriculum. This is the mistake that Joaquim, José, Federico, etc., report in their narratives.

But it is also true that many teachers have a positive attitude towards Roma students. They care about finding ways to teach mathematics to Roma children who struggle with them (as well as other children who also have troubles with this subject). This finding is consistent with previous literature highlighting the important role that teachers can play to transform learning and overcome structural inequalities [69]. As in the cases reported here, there are many teachers who really want to help Roma children, and they work hard to do so; but, sometimes good will is not enough. Willing to do their best, some teachers separate Roma children rather than including them within the mainstream. They provide additional support, but this fact leads Roma children to feel different from their classmates (in a negative way). The six narratives we have discussed here suggest that success happens (or is more likely to happen) when Roma children are not separated away from their group of peers. Contrarily, failure appears to be connected with ability grouping more frequently.

The role of the family also plays a crucial role in order to overcome the difficulties and barriers that some Roma students face along their school trajectories [71]. The family may be a resource. However, many Roma families struggle and look for further resources to reinforce their children's learning. Recent studies suggest that family engagement has a major impact on learning than just appointing family members in the school to 'report' on children's behaviour or achievement [72]. Having an academic background is not a sine qua non condition for families to apply/use successful educational actions [73]. Illiterate families can also become 'resources' having a great (and crucial) positive impact on their children's learning.

In order to develop a successful educational story, it is necessary to rethink some of the practices that have resulted in segregating Roma students instead of including them. Joana and Federico are unequivocal in this aspect: many times, they explain that if they reached the University it was because, among other aspects, they were never segregated in their academic trajectories; they always were with the mainstream. That was a crucial element because they had the same opportunities as their peers; they learned the same curriculum, with the same tasks, in an inclusive and equitable educational environment.

\section{Conclusions}

Education is one of the cornerstones to achieving a sustainable world [74]. Different declarations within the current global agenda planning the future for a sustainable world identify education as a key element to develop sustainable-focused strategies for a more responsible future. Education is linked to "responsible citizenship", "ethical awareness", "having values, skills and attitudes consistent with sustainable development", and so forth. Different documents such as the Education for Sustainable 
Development Goals [75] or the Roadmap for Implementing the Global Action Programme on Education for Sustainable Development [76] draw on this idea about education.

Actually, the impact of education to achieve sustainable development has been universally proved. Fighting against poverty, eliminating hunger, having a good health and well-being, eradicating gender inequalities, or having decent employment conditions, among others, have a common denominator: high quality education. Without access to, at least, compulsory education, people are exposed to deprivation, poverty, and many other situations of marginalization. Education not only provides opportunities but also protection in a society where high-qualified, technological, expert and mathematics-based opportunities are more and more common. Statistical data available $[7,17]$ have already demonstrated the strong correlation between education and sustainability. Deprivation and exclusion are also linked significantly with early school leaving and drop out, especially among ethnic and cultural minorities, in every region in the world. Obtaining low scores in mathematics is especially relevant as a predictor of drop out, tracking and streaming.

In this article, we have identified five promising characteristics that emerged in the educational trajectories of six Roma students who succeeded against the odds: identity, teachers' role, family support, peer-to-peer interactions and individual learning strategies for studying. The data discussed suggest that in order to include students from minority groups, such as Roma, we do not need to adapt the curriculum of mathematics to present it to them in a more oral way, which draws upon an assumption of the typified idea of Roma being good in the mental calculation because of their cultural heritage. What we need to do is to transform the learning context of these children, providing them interactions grounded on high expectations, not in prejudice or negative social representations. When there is a positive context, grounded on high expectations, Roma students are more likely to succeed in education, as it happens with the non-Roma. This occurs when teachers, families and other members of the community support these children to push them throughout the learning process.

Joaquim, Aroa, Joana, Federico, José, and Antonio have different school experiences. However, all of them share the same passion for learning. The analysis of their narratives suggests that success is related to holding positive attitudes. A positive social context is crucial to understand why all these six Roma individuals have had success in their academic lives. Family, friends, and teachers are part of this social context. The six Roma participants interviewed claim that they were able to develop successful academic strategies (using outlines, doing homework, studying, etc.) because of the support received in a number of different situations by one (or more) of these agents (family, friends, and teachers).

However, we still need further quantitative and qualitative research to control the features that emerged in their educational trajectories already identified in this article as "explicative factors" of the participants. We need further empirical data to explore if is there any type of causality between the five aspects identified here and Roma students' success in education. Further research is needed to find the betha $(\beta)$ coefficients to better understand which one of these five variables have a greater impact on successful learning. There is also a need for more accuracy in the definitions of the variables, in terms of the operationalization of this tool as a methodological tool for further research. We have just opened this field of research, moving beyond anthropological, ethnographic and cultural approaches, towards a dialogic approach including the voices of the Roma people themselves. But we know that we must persevere in this effort because we need solid methodological instruments to guide our research in order to find contributions that might inform in-service and pre-service teachers' practices, in order to improve the mathematics teaching and learning and, eventually, fulfil the global goal of ensuring inclusive and quality education for all.

Author Contributions: Conceptualization, J.D.-P.; Formal analysis, S.M.-R.; Investigation, J.D.-P., Ainhoa Flecha and S.M.-R.; Methodology, A.F.F.d.S.; Validation, R.G.-C.; Writing-original draft, J.D.-P.; Writing—review \& editing, R.G.-C.

Funding: This research received no external funding.

Conflicts of Interest: The authors declare no conflict of interest. 


\section{References}

1. Apple, M.W. Can Education Change Society? Routledge: New York, NY, USA; London, UK, 2013; ISBN 978-0-41-58753-2.

2. Flecha, R. The dialogic sociology of education. Int. Stud. Soc. Educ. 2011, 21, 7-20. [CrossRef]

3. Shor, I.; Freire, P. A Pedagogy for Liberation: Dialogues on Transforming Education; Bergin \& Garvey: Westport, CT, USA; London, UK, 1987; ISBN 0-89789-104-X.

4. UN. Goal 4: Ensure Inclusive and Quality Education for All and Promote Lifelong Learning. Available online: https: / / www.un.org/sustainabledevelopment/education/ (accessed on 15 May 2018).

5. Šlaus, I.; Jacobs, G. Human capital and sustainability. Sustainability 2011, 3, 97-154. [CrossRef]

6. Wulf, C. Human development in a globalized world. Education towards peace, cultural diversity and sustainable development. Revista Española de Pedagogía 2013, 71, 71-86.

7. Eurostat. Statistics explained. Quality of Life Indicators-Education. Main Statistical Findings. Level of Educational Attainment. Available online: http:/ / ec.europa.eu/eurostat/statistics-explained/index.php/ Quality_of_life_indicators_-_education (accessed on 8 June 2018).

8. Ladson-Billings, G. It doesn't add up: African American students' mathematics achievement. J. Res. Math. Educ. 1997, 28, 697-708. [CrossRef]

9. Martin, D.B.; Gholson, M.L.; Leonard, J. Mathematics as gatekeeper: Power and privilege in the production of knowledge. J. Urban Math. Educ. 2010, 3, 12-24.

10. Parker, P.D.; Marsh, H.W.; Ciarrochi, J.; Marshall, S.; Abduljabbar, A.S. Juxtaposing math self-efficacy and self-concept as predictors of long-term achievement outcomes. Educ. Psychol. 2014, 34, 29-48. [CrossRef]

11. Balfanz, R.; Herzog, L.; Mac Iver, D.J. Preventing student disengagement and keeping students on the graduation path in urban middle-grades schools: Early identification and effective interventions. Educ. Psychol. 2007, 42, 223-235. [CrossRef]

12. Tate, W. Race-ethnicity, SES, gender and language proficiency trends in mathematics achievement:An update. J. Res. Math. Educ. 1997, 286, 652-679. [CrossRef]

13. Duque, E. Inventing the Mathematician. Gender, Race, and Our Cultural Understanding of Mathematics. REDIMAT 2016, 5, 205-207. [CrossRef]

14. Gorard, S.; Smith, E. Do barriers get in the way? A review of the determinants of post-16 participation. Res. Post Compuls. Educ. 2007, 12, 141-158. [CrossRef]

15. Catarci, M. Intercultural education in the European context: Key remarks from a comparative study. Intercult. Educ. 2014, 25, 95-104. [CrossRef]

16. OECD. Education at a Glance 2017. OECD Indicators; OECD Publishing: Paris, France, 2017.

17. UNESCO. Handbook on Measuring Equity in Education; UNESCO Institute for Statistics: Montreal, QC, Canada, 2018; ISBN 978-9-29-189227-3.

18. Fundación Secretariado General Gitano. Statistical Data. Available online: https://www.gitanos.org/quehacemos/areas/educacion/index.html (accessed on 15 May 2018).

19. Ainscow, M.; Sandill, A. Developing inclusive education systems: The role of organisational cultures and leadership. Int. J. Incl. Educ. 2010, 14, 401-416. [CrossRef]

20. Girbés, S.; Macías, F.; Álvarez, P. De la escuela gueto a una comunidad de aprendizaje: Un estudio de caso sobre la superación de la pobreza a través de una educación de éxito. Int. Multidiscip. J. Soc. Sci. 2015, 4, 88-116. [CrossRef]

21. Gurzó, K. Does the SEN Category Discriminate Roma Children (only)? Procedia Soc. Behav. Sci. 2014, 116, 5030-5035. [CrossRef]

22. Petrokou, E.; Dimitrakopoulas, I.N. Racism and Local Authorities: The Case of Roma in Nea Kios; ANTIGONE RAXEN National Focal Point: Athens, Greece, 2002.

23. New, W.; Merry, M.S. Learning who they 'really' are: From stigmatization to opportunities to learn in Greek Romani education. In International Handbook of Migration Minorities and Education; Bekerman, Z., Geisen, T., Eds.; Springer: New York, NY, USA, 2012; pp. 623-639, ISBN 978-9-40-071465-6.

24. Revenga, A.; Ringold, D.; Tracy, W.M. Poverty and Ethnicity: A Cross-Country Study of Roma Poverty in Central Europe; World Bank Publications: Washington, DC, USA, 2002; ISBN 0-8213-5339-X.

25. Fox, J. Patterns of discrimination, grievances and political activity among Europe's Roma: A cross-sectional analysis. JEMIE J. Ethnopolitics Minor. Issues Eur. 2001, 1, 1-25. 
26. Chronaki, A. Learning about 'learning identities' in the school arithmetic practice: The experience of two young minority Gypsy girls in the Greek context of education. Eur. J. Psychol. Educ. 2005, 20, 61-74. [CrossRef]

27. Sordé, T.; Serradell, O.; Puigvert, L.; Munté, A. Solidarity networks that challenge racialized discourses: The case of Romani immigrant women in Spain. Eur. J. Women's Stud. 2014, 21, 87-102. [CrossRef]

28. Cavalli-Sforza, L.; Cavalli-Sforza, F. The Great Human Diasporas: The History of Diversity and Evolution; Addison-Wesley: New York, NY, USA, 1995; ISBN 978-0-20-144231-1.

29. Dafermos, M. Marginalisation and Educational Inclusion; Atrapos: Athens, Greece, 2006.

30. Hancock, I. Reunification and the role of international Romani Union. Roma 1988, 29, 9-19.

31. Okely, J. Changing Cultures: The Traveller-Gypsies; Cambridge University Press: Cambridge, UK, 1983; ISBN 0-521-24641-5.

32. Okely, J. Some political consequences of theories of Gypsy ethnicity: The place of the intellectual. In After Writing Culture: Epistemology and Praxis in Contemporary Anthropology; James, A., Hockney, J., Dowson, A., Eds.; Routledge: London, UK, 1997; ISBN 0-203-45098-1.

33. Flecha, R.; Soler, M. Turning difficulties into possibilities: Engaging Roma families and students in school through dialogic learning. Camb. J. Educ. 2013, 43, 451-465. [CrossRef]

34. Chronaki, A. An entry to dialogic in the Maths classroom: Encouraging hybrid learning identities. In Social Interactions in Multicultural Settings; César, M., Kumpulainen, K., Eds.; Sense Publishers: Rotterdam, The Netherlands; Taipei, Taiwan, 2008; pp. 117-144, ISBN 978-9-08-790716-7.

35. Kertesi, G.; Kézdia, G. The Roma/non-Roma test score gap in Hungary. Am. Econ. Rev. 2011, 101, $519-525$. [CrossRef]

36. Stathopoulou, C.; Kalabasis, F. Language and culture in Mathematics Education: Reflections on Observing a Romany Class in a Greek School. Educ. Stud. Math. 2007, 64, 231-238. [CrossRef]

37. Bernstein, B. Structuring of Pedagogic Discourse; Routledge: London, UK, 2003; ISBN 0-203-01126-0.

38. Bourdieu, P. La Distinction: Critique Sociale du Jugement; Minuit: Paris, France, 2016; ISBN 978-2-70-233721-4.

39. Hudley, C. Achievement and Expectations of Immigrant, Second Generation, and Non-immigrant Black Students in U.S. Higher Education. Int. J. Educ. Psychol. 2016, 5, 223-248. [CrossRef]

40. Gutiérrez, K.D.; Baquedano-López, P.; Tejeda, C. Rethinking diversity: Hybridity and hybrid language practices in the third space. Mind Cult. Act. 1999, 6, 286-303. [CrossRef]

41. Bakhtin, M.M. The Dialogic Imagination: Four Essays; University of Texas Press: Austin, TX, USA, 2010; Volume 1, ISBN 978-0-292-71534-2.

42. Flick, U. Design and process in qualitative research. In A Companion to Qualitative Research; Flick, U., von Kardorff, E., Steinke, I., Eds.; Sage: Thousand Oaks, CA, USA; London, UK; New Delhi, India, 2004; pp. 146-152, ISBN 0761973745.

43. Blumer, H. Symbolic Interactionism. Perspective and Method; Prentice Hall: Englewood Cliffs, NJ, USA, 1969; ISBN 0520056760.

44. Bruner, J. Acts of Meaning; Harvard University Press: Cambridge, MA, USA, 1990; ISBN 0-674-00360-8.

45. Merkens, H. Selection procedures, sampling, case construction. In A Companion to Qualitative Research; Flick, U., von Kardorff, E., Steinke, I., Eds.; Sage: Thousand Oaks, CA, USA; London, UK; New Delhi, India, 2004; pp. 165-171, ISBN 0761973745.

46. Flecha, R.; Gómez, J. Participatory paradigms: Researching 'with' rather than 'on'. In Researching Widening Access to Lifelong Learning; Osborne, M., Gallacher, J., Crossan, B., Eds.; Routledge: London, UK, 2002; pp. 129-140, ISBN 0203338723.

47. European Commission. Ethics for Researchers. Facilitating Research Excellence in FP7; Directorate-General for Research and Innovation. Directorate B-European Research Area; Publications Office of the European Union: Luxembourg, 2013.

48. Thomas, W.I.; Znaniecki, F. The Polish Peasant in Europe and America; Alfred, A., Ed.; Knopf: New York, NY, USA, 1927; ISBN 0-252-06484-4.

49. Garfinkel, H. Studies in Ethnomethodology; Prentice-Hall: Englewood Cliffs, NJ, USA, 1967; ISBN 978-0-74-560005-5.

50. Mills, C.W. The Sociological Imagination; Oxford University Press: New York, NY, USA, 2000; ISBN 978-0-19-513373-8.

51. Beverly, J. Testimonio, subalternity, and narrative authority. In The SAGE Handbook of Qualitative Research, 3rd ed.; Denzin, N.K., Lincoln, Y., Eds.; Sage: Thousand Oaks, CA, USA; London, UK; New Delhi, India, 2005; pp. 547-557, ISBN 0-7619-2757-3. 
52. Mertens, D.M. Transformative Research and Evaluation; Guilford Press: New York, NY, USA, 2009; ISBN 978-1-59385-302-0.

53. Mertens, D.M. Transformative mixed methods research. Qual. Inq. 2010, 16, 469-474. [CrossRef]

54. Glaser, B.G.; Strauss, A.L. Discovery of Grounded Theory: Strategies for Qualitative Research; Routledge: New York, NY, USA, 2017; ISBN 978-0-202-30260-7.

55. Aubert, A. Amaya: Dialogic literary gatherings evoking passion for learning and a transformation of the relationships of a Roma girl with her classmates. Qual. Inq. 2015, 20, 858-864. [CrossRef]

56. Sánchez, M.; Yuste, M.; de Botton, L.; Kostic, R. Communicative Methodology of Research with Minority Groups. Int. Rev. Qual. Res. 2013, 6, 226-238. [CrossRef]

57. Habermas, J. The Theory of Communicative Action; Beacon: Boston, MA, USA, 1984; Volume I, ISBN 978-080-701506-3.

58. Dweck, C.S. Mindset: The New Psychology of Success; Ballantine Books: New York, NY, USA, 2014; ISBN 978-0-345-47232-8.

59. Hattie, J. Teachers Make a Difference, What is the Research Evidence? In Building Teacher Quality: What Does the Research Tell Us? Australian Council for Educational Research (ACER). ACEReSearch. Available online: https:/ / bit.ly/2KV4dBT (accessed on 15 May 2018).

60. Darling-Hammond, L. Teacher quality and student achievement. Educ. Policy Anal. 2000, 8. [CrossRef]

61. Moll, L.C.; Amanti, C.; Neff, D.; Gonzalez, N. Funds of knowledge for teaching: Using a qualitative approach to connect homes and classrooms. Theory Pract. 1992, 31, 132-141. [CrossRef]

62. Subero, D.; Vila, I.; Esteban-Guitart, M. Some contemporary forms of the Funds of Knowledge approach. Developing culturally responsive pedagogy for social justice. Int. J. Educ. Psychol. 2015, 4, 33-53. [CrossRef]

63. Moscovici, S. On social representations. Soc. Cogn. Perspect. Everyday Underst. 1981, 8, 181-209.

64. Csepeli, G.; Simon, D. Construction of Roma identity in Eastern and Central Europe: Perception and self-identification. J. Ethn. Migr. Stud. 2004, 30, 129-150. [CrossRef]

65. Hoover-Dempsey, K.V.; Walker, J.M.; Sandler, H.M.; Whetsel, D.; Green, C.L.; Wilkins, A.S.; Closson, K. Why do parents become involved? Research findings and implications. Elem. School J. 2005, 106, 105-130. [CrossRef]

66. Mead, G.H. Mind, Self and Society; University of Chicago Press: Chicago, IL, USA, 1934; ISBN 978-0-22-651660-8.

67. Rosenthal, R.; Jacobson, L. Pygmalion in the classroom. Urban Rev. 1968, 3, 16-20. [CrossRef]

68. Willis, P.E. Learning to Labor: How Working Class Kids Get Working Class Jobs; Columbia University Press: New York, NY, USA, 1977; ISBN 978-1-13-842184-4.

69. Panthi, R.K.; Luitel, B.C.; Belbase, S. Teachers' perception of social justice in mathematics classrooms. REDIMAT 2018, 7, 7-37. [CrossRef]

70. Vargas, J.; Gómez, J. Why Roma do not like mainstream schools: Voices of a people without territory. Harv. Educ. Rev. 2003, 73, 559-590. [CrossRef]

71. Tellado, I. Bridges between individuals and communities: Dialogic participation fueling meaningful social engagement. Res. Ageing Soc. Policy 2017, 5, 8-31. [CrossRef]

72. García-Carrión, R.; Díez-Palomar, J. Learning Communities: Pathways for educational success and social transformation through interactive groups in mathematics. Eur. Educ. Res. J. 2015, 14, 151-166. [CrossRef]

73. Valls, R.; Kyriakides, L. The power of Interactive Groups: How diversity of adults volunteering in classroom groups can promote inclusion and success for children of vulnerable minority ethnic populations. Camb. J. Educ. 2013, 43, 17-33. [CrossRef]

74. UN. Resolution Adopted by the General Assembly on 25 September 2015. 70/1. Transforming Our World: The 2030 Agenda for Sustainable Development. UN. A/RES/70/1. Available online: http:/ /www.un.org/ ga/search/view_doc.asp?symbol=A/RES/70/1\&Lang=E (accessed on 15 May 2018).

75. UNESCO. Education for Sustainable Development Goals. Learning Objectives; UNESCO: Paris, France, 2017; Available online: http:/ / unesdoc.unesco.org/images/0024/002474/247444e.pdf (accessed on 15 May 2018).

76. UNESCO. Roadmap for Implementing the Global Action Programme on Education for Sustainable Development; UNESCO: Paris, France, 2014; Available online: http:/ / unesdoc.unesco.org/images /0023/002305/230514e. pdf (accessed on 15 May 2018).

(C) 2018 by the authors. Licensee MDPI, Basel, Switzerland. This article is an open access article distributed under the terms and conditions of the Creative Commons Attribution (CC BY) license (http:/ / creativecommons.org/licenses/by/4.0/). 